Open Access

\title{
Assessing the Impact of Tiotropium on Lung Function and Physical Activity in GOLD Stage II COPD Patients who are Naïve to Maintenance Respiratory Therapy: A Study Protocol
}

\author{
Thierry Troosters ${ }^{*}, 1$, Idelle Weisman ${ }^{2}$, Fabienne Dobbels ${ }^{3}$, Nicholas Giardino ${ }^{4}$ and \\ Srinivas Rao Valluri ${ }^{5}$
}

\author{
${ }^{I}$ Pulmonary Rehabilitation and Respiratory Division, UZ Gasthuisberg, Leuven, Belgium, and Department of \\ Rehabilitation Sciences, KU-Leuven, Belgium \\ ${ }^{2}$ Medical Affairs-Respiratory, Primary Care Business Unit, Pfizer, Inc., New York, NY, USA \\ ${ }^{3}$ Center for Health Services and Nursing Research, KU-Leuven, Leuven, Belgium \\ ${ }^{4}$ Department of Psychiatry, University of Michigan Medical Center, Ann Arbor, MI USA \\ ${ }^{5}$ Statistics, Specialty Care Business Unit, Pfizer, Inc., New York, NY, USA
}

\begin{abstract}
Physical activity status is increasingly recognized as a reliable predictor of mortality and hospitalization in patients with chronic obstructive pulmonary disease (COPD). The reduction in physical activity occurs earlier in the clinical course of COPD than previously appreciated, possibly arising from breathlessness, reduced exercise tolerance, and adoption of a more sedentary lifestyle. To date, no clinical trial has evaluated the impact of pharmacotherapy on both lung function and physical activity. We recently designed a study that evaluates the impact of tiotropium (a once-daily inhaled anticholinergic) on lung function and physical activity in a maintenance/treatment-naïve Global Initiative for Chronic Obstructive Lung Disease (GOLD) Stage II COPD cohort. Previous studies have demonstrated that tiotropium improves lung function and exercise tolerance; whether these benefits translate into improvements in physical activity is the focus of the current work. Here we describe the rationale and challenges in developing and implementing this study and review its unique features and novel design, including: utility of direct activity monitoring in multi-center clinical trials; importance of behavioral-modification techniques (including motivational interviewing to improve patient selfefficacy and adherence for a healthy, more active lifestyle); utility of individualized activity plans that provide an integrated approach with pharmacotherapy and behavioral modification to help patients achieve a more active lifestyle.
\end{abstract}

Keywords: COPD, physical activity, activity monitor, tiotropium, methodology, study design.

\section{INTRODUCTION}

Physical inactivity is associated with poor long-term outcomes, including hospitalizations and mortality in chronic obstructive pulmonary disease (COPD) $[1,2]$. Moreover, higher physical activity levels decrease the risk of developing cardiovascular and metabolic diseases [3, 4], which are important co-morbidities in COPD. Consequently, maintaining physical activity is considered an important treatment goal for these patients because the potential impact for reduction in co-morbidities is especially important in early disease [5].

Patients with Global Initiative for Chronic Obstructive Lung Disease (GOLD) Stage II COPD are reported to be more physically inactive compared with healthy control subjects [6-8]. Although improvements in exercise tolerance and exertional dyspnea have been convincingly shown in moderate COPD, there is only circumstantial evidence that

\footnotetext{
*Address correspondence to this author at the Pulmonary Rehabilitation and Respiratory Division, UZ Gasthuisberg, Leuven, Belgium; Tel: + 321634 71 07; Fax: + 32163471 26; E-mail: thierry.troosters@med.kuleuven.be
}

bronchodilator therapy may enhance physical activity levels in patients with COPD $[9,10]$. First, dynamic hyperinflation contributes to exercise-related symptoms in early disease $[11,12]$ and it is related to physical activity levels - daily physical activity in patients with COPD is mainly associated with dynamic hyperinflation [13]. Dynamic hyperinflation is alleviated by bronchodilator therapy [14]. Second, a subanalysis of the Understanding Potential Long-term Impacts on Lung Function with Tiotropium (UPLIFT ${ }^{\circledR}$ ) trial suggested that the long-acting anticholinergic agent, tiotropium, could be used successfully as a first-line maintenance therapy in COPD to improve quality of life, particularly in the domain of physical activity [15]; other benefits were enhanced lung function and reduced exacerbation rate. The latter may be of particular importance as exacerbations lead to long-term reductions in physical activity. Lastly, exercise tolerance and symptoms associated with physical activity were reported to be improved when bronchodilators were administered to patients with GOLD Stage II COPD $[9,10]$.

Another important but poorly studied problem in early COPD is the increased rate and costs of disability in those 
COPD patients who are of working age [16]. It may be worthwhile to investigate the impact of optimizing pharmacotherapy on worker productivity as well.

We hypothesized that, if lung function improvement can be sustained or even improved early in the disease, this may potentially impact on both short- and long-term improvements in patient-centered outcomes such as symptoms, health-related quality of life (HRQoL) and physical activity [17]. To test this hypothesis, we designed a multi-center clinical trial to evaluate the impact of pharmacologic intervention with the inhaled once-daily anticholinergic agent, tiotropium, on lung function and the amount of physical activity using an activity monitoring device in COPD. Tiotropium significantly improves breathlessness, lung function, and exercise tolerance (cycle ergometry endurance time) in patients with COPD $[9,10]$ and has been shown to improve treadmill endurance time, especially when added to pulmonary rehabilitation [18]. To our knowledge, this is the first time physical activity in COPD during pharmacologic intervention in a multi-center trial has been systematically examined using an activity monitoring device.

Here we describe the methodology and discuss the challenges associated with the implementation of a multicenter clinical trial assessing lung function and physical activity with pharmacologic intervention in patients with GOLD Stage II COPD who are not receiving maintenance therapy (maintenance naïve).

\section{METHODS}

\section{Study Objectives}

The primary objective of this trial (NCT00523991) is to assess the efficacy and safety of tiotropium $18 \mu \mathrm{g}$ inhalation capsule via HandiHaler ${ }^{\circledR}$ compared with placebo in subjects with moderate COPD (post-bronchodilator forced expiratory volume in 1 second $\left[\mathrm{FEV}_{1}\right] 50-80 \%$ predicted; GOLD Stage II) who have not previously been treated with maintenance therapy, i.e. who have only been treated with short-acting $\beta$ agonists on an as-needed basis in the 6 months prior to study enrollment and who have symptomatic shortness of breath.

\section{Study Design}

This is a 24-week, randomized, double-blind, placebocontrolled, multinational study, involving a target sample size of approximately 436 maintenance-naïve patients with Stage II COPD (Fig. 1). The primary endpoint is lung function improvement as captured by the area under the curve (AUC) of $\mathrm{FEV}_{1}$ versus time $\left(\mathrm{FEV}_{1 \mathrm{AUC}}\right.$ 0-3h). Lung function is assessed before (trough) and after administration of the study drug and patients are monitored for 3 hours after administration. Physical activity is assessed during the week prior to each study visit, using a validated activity monitor as a secondary endpoint. Additional secondary objectives include the effect of tiotropium treatment on other lung function variables, patient and physician global evaluations, worker productivity as assessed by the Work Productivity and Activity Impairment questionnaire [19], and the use of rescue medication. Information on COPD exacerbations is collected through serious adverse event monitoring.

\section{Study Population}

Eligible patients have a clinical diagnosis of COPD according to GOLD guidelines criteria; post-bronchodilator $\mathrm{FEV}_{1} /$ forced vital capacity (FVC) $<70 \%$ [5]; be aged $40-80$ years; men or women; be current or former smoker with a smoking history $\geq 10$ pack years; have a post-bronchodilator $\mathrm{FEV}_{1} \geq 50 \%$ and $<80 \%$ predicted normal value $[5,20,21]$; and symptoms of dyspnea when walking on an incline (dyspnea grade $\geq 2$ ) [22]. Prior to randomization, all patients are required to pass an exercise stress test [23, 24], perform spirometry satisfactorily, and to demonstrate compliance with wearing the activity monitor and using the HandiHaler ${ }^{B}$ device. At screening, after downloading the patients' activity monitor data, a compliance and activity report is generated. Compliance with the activity monitor was prospectively defined as use $\geq 80 \%$ of time during waking hours for approximately 14 hours/day, 7 days/week. The exact definition of compliance with the activity monitor to be used in the statistical analysis will be determined after assessment of the distribution of the blinded data.

Patients are excluded if they: (1) were treated with maintenance respiratory medications within the 6 months prior to screening; (2) had an upper respiratory tract infection or COPD exacerbation in the 6 weeks prior to the screening visit or during the screening visit prior to Visit 3; (3) had non-pulmonary disease that would limit physical activity (e.g. arthritis, amputation); (4) had a history of asthma, cystic fibrosis, pulmonary fibrosis, bronchiectasis, pulmonary resection or other significant respiratory disorders other than COPD; (5) had significant diseases other than COPD which, in the opinion of the investigator, may influence the results of the study or the patient's ability to participate; (6) contraindication to exercise testing; (7) had prior participation (within 2 years) of either cardiac or pulmonary rehabilitation.

\section{Interventions}

Eligible patients are randomized to receive either tiotropium $(18 \mu \mathrm{g})$ via HandiHaler ${ }^{\circledR}$ plus as-needed albuterol (salbutamol), or placebo via HandiHaler ${ }^{\circledR}$ plus as-needed albuterol, and seen at monthly intervals thereafter until study completion. Open-label albuterol can be used as rescue medication and the number of puffs per day noted in the patient diary. There are no restrictions for medications prescribed for treatment of exacerbations as long as they are used for fewer than 2 cumulative weeks.

\section{Procedures}

\section{Spirometry}

Pulmonary function tests are performed at baseline and at Weeks 8, 16, and 24 and are in accordance with criteria established by the American Thoracic Society and European Respiratory Society [25-27]. FEV 1 and FVC are assessed at several time points: before (trough: 24 hours after the previous dose and 10 minutes prior to the next dose) and after $(30,60,120$, and 180 minutes) inhalation of the study drug. Post-bronchodilator testing is performed at the screening visit only for disease staging. 


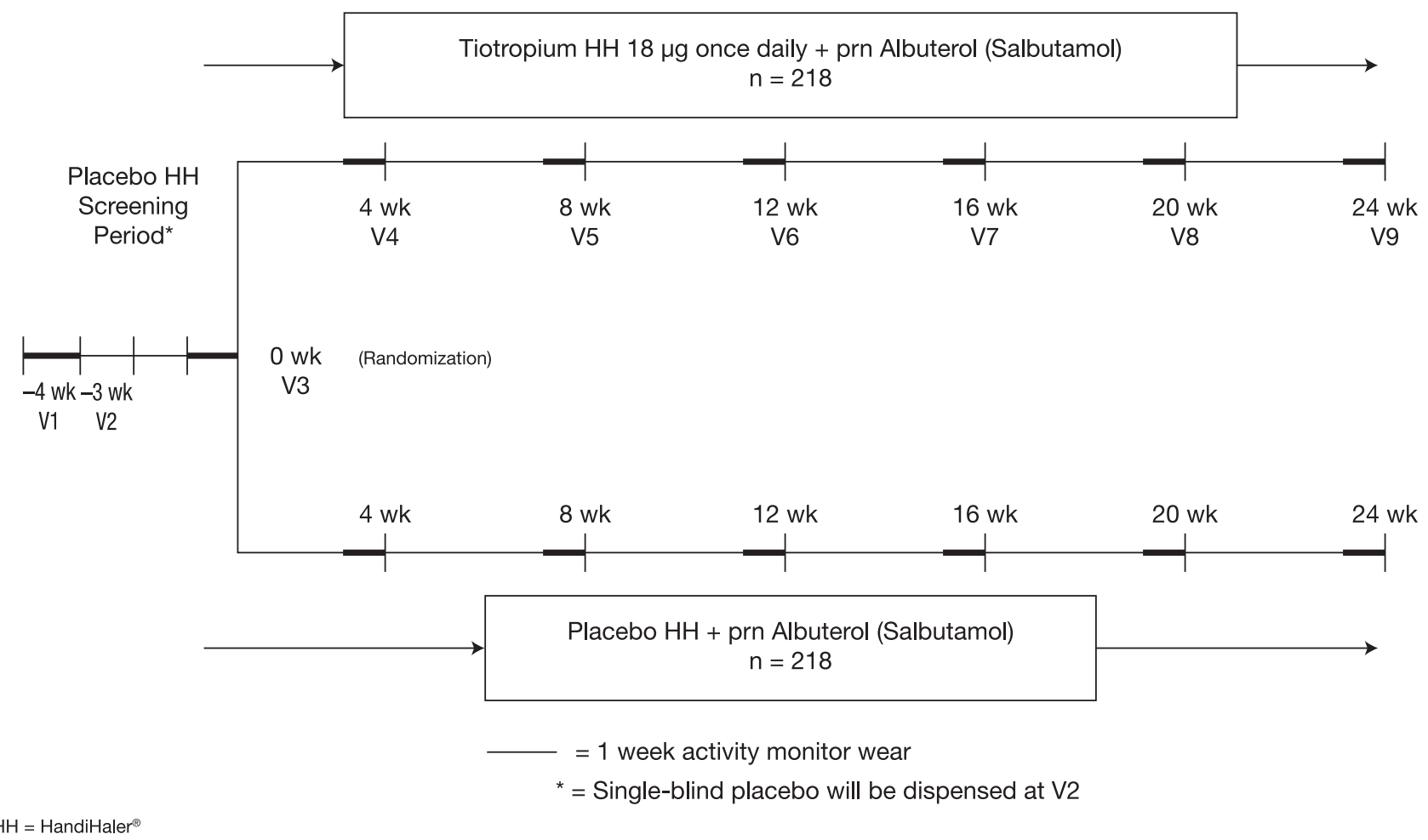

Fig. (1). Study design. The study consists of nine clinic visits (V1-V9) over 28 weeks. There is a 4-week screening period that includes Visit 1/Week -4 with single-blind placebo run-in at Visit 2/Week -3; and a 24-week double-blind phase that includes Visit 3/Week 0 (baseline), Visit 4/Week 4, Visit 5/Week 8, Visit 6/Week 12, Visit 7/Week 16, Visit 8/Week 20 and Visit 9/Week 24 (end of the study).

\section{Physical Activity Using the Activity Monitor}

Physical activity and estimated energy expenditure over time are determined by the activity monitor. Patients undergo two separate 1-week familiarization/training sessions for the physical activity monitor (SenseWear ${ }^{B}$ Armband $^{\circledR}$; BodyMedia, Pittsburgh, PA, USA). Reminder telephone calls prompt the wearing of the physical activity monitor for the week prior to each study visit.

The SenseWear ${ }^{\circledR}$ Armband $^{\circledR}$ is a lightweight $(80 \mathrm{~g})$, multi-sensor device worn on the right upper arm (triceps) that assesses acceleration in two planes (i.e. bi-axial accelerometer), skin temperature, near body temperature, and galvanic skin response. Energy expenditure is based on algorithms in the software (SenseWear ${ }^{B}$ 6.1). The device has been validated for use in several populations previously, including COPD [28, 29], and data comparing COPD with age-matched healthy controls are available [4, 7, 15, 29]. Patients are instructed to wear the armband for a week and for as long as they can during the day, preferably $>14$ hours/day, only removing it for personal hygiene (avoiding water contact).

Compliance with wearing the activity monitor in minutes per day is recorded. Analysis of physical activity endpoints will be based as Activity Evaluable Set (ACTES) defined as subjects who use their armband at least for 4 days a week for at least 11 hours per day and have physical activity and energy expenditure data available for $\geq 12$ weeks. Parameters of physical activity and energy expenditure (over time, using age-appropriate pre-defined activity metabolic equivalent
[MET]) as determined by the activity monitor include: (1) Average time spent per day in: light intensity (1.5-3 METS) activity; moderate or higher intensity ( $\geq 3$ METS) activity [30-33]; (2) healthy lifestyle (defined as 30 minutes of activity $>3$ METS for $70 \%$ of eligible days according to ACTES) [31]; (3) the average Active Energy Expenditure (kcals spent in activities noted above and previously expressed as METS per day); (4) the average number of steps per day.

\section{Patient Diary}

Patients are required to maintain a diary throughout the study that includes self-reporting of daily rescue albuterol inhalations, information on breathlessness, and the 10-point modified BORG scale data for gauging intensity of physical activity.

\section{Behavioral Modification Intervention}

In order to raise the awareness on the importance of adopting a physically active lifestyle, and to facilitate the transition towards a more active lifestyle, all patients receive behavioral intervention focused on enhancing physical activity levels. This intervention, integrated into the clinical visits, consists of: (1) a monthly face-to-face 20-minute consultation with site personnel who were trained to discuss physical activity levels and set goals trying to enhance physical activity; (2) an individual activity action plan based on the patient's current physical activity levels, indicating a possible and individualized step-up program; and (3) provision of educational material in the format of a DVD. 
Motivational interviewing principles are applied in faceto-face meetings with the patient. Motivational interviewing is a client-centered, directive method of conversation with patients to enhance intrinsic motivation to change behavior (in this case physical activity) by exploring and resolving ambivalence [34]. The emphasis is on eliciting the person's intrinsic motivation for change. Change is usually accomplished incrementally with small steps.

\section{Activity Plan}

Every month, all patients receive an individualized activity plan based on the previous month's downloaded activity monitor data, coupled with the review of the previous month's activity diaries. At each study visit, the data from the activity monitor is downloaded and a report generated that formed the basis of the 20- to 30-minute faceto-face discussion for the individualized activity plan. The activity plan is essentially a guided step-up plan towards enhanced physical activity based on the patient's current measured activity level (Fig. 2). Using motivational interview techniques, trained site staff discuss the current physical activity levels with the patient and his/her willingness to engage in more physical activities if needed.

\section{Statistical Methods}

The sample size estimation was based on the Swedish "Mild" results using a conservative estimate of $300 \mathrm{~mL}$ for the standard deviation of $\mathrm{AUC}_{0-3 \mathrm{~h}} \mathrm{FEV}_{1}$ [35]. A sample size of 382 patients is required in order to detect a $100-\mathrm{mL}$ difference in mean $\mathrm{AUC}_{0-3 \mathrm{~h}} \mathrm{FEV}_{1}$ between the tiotropiumand placebo-treatment groups at Week 24 with 5\% level of significance with $90 \%$ power using a two-tailed $t$-test. An estimated drop-out rate of $12 \%$ was used to determine the final target sample size of 436 patients.

Efficacy analyses for lung function will be performed on each group and will be expressed as an improvement of $\mathrm{FEV}_{1} \mathrm{AUC}_{0-3 \mathrm{~h}}$ response from baseline to Week 24 (end of treatment). Response is defined as the change from baseline (Week 0) to 3 hours' post-dose $\mathrm{FEV}_{1} \mathrm{AUC}_{0-3 \mathrm{~h}}$ at the final visit (Week 24). AUC is computed using the trapezoidal rule and normalized by dividing by 3 hours. All hypotheses will be tested using a Type I error rate of 0.05 . All statistical tests will be performed as two-sided tests. The primary efficacy analysis for $\mathrm{FEV}_{1} \mathrm{AUC}_{0-3 \mathrm{~h}}$ will be performed using an analysis of covariance (ANCOVA) model with terms for treatment group and investigator site, and baseline value as covariate. All continuous variables will be analyzed by ANCOVA models, with terms for treatment group and investigator site, and baseline value as covariate. Categorical variables will be analyzed by Cochran-Mantel-Hansel tests $[36,37]$ with investigator site as the stratification variable. If distributional assumptions for parametric models are violated, then non-parametric methods will be used.

Data on physical activity and energy expenditure endpoints will be collected throughout the duration of the study and analyzed using the previously defined ACTES. Physical activity and energy expenditure over time in each group will be expressed as an improvement of parameter response from baseline to Week 24 (end of treatment). Response is defined as the change from baseline to Week 24. Analysis will be conducted using ANCOVA and will be adjusted for baseline value and site.

The proportion of patients meeting criteria for a healthy lifestyle (based on time spent in moderate activity and steps) will be calculated and compared.

Correlation analyses of activity monitor outputs as measured by the time spent per day in all physical activities using age appropriate pre-defined activity MET levels at the baseline with the Clinical COPD Questionnaire [38] and the Chronic Respiratory Disease Questionnaire [39-41], respectively, will be conducted as an exploratory analysis.

\section{DISCUSSION}

The diagnosis of COPD using spirometry, although recommended, usually does not occur until symptoms become evident and until late in the course of the disease. Consequently, little is known about the treatment strategies and potential benefits of maintenance therapy in patients with earlier stage disease who are maintenance naïve. The challenge in this patient cohort is to relate the impact of maintenance therapy on lung function for the short- and long-term with enduring patient-centered healthcare benefits. The present study addresses this challenge by analyzing the effect of tiotropium as first-line maintenance therapy on lung function and, secondly, analyzing the impact of tiotropium on pulmonary function, physical activity levels, and work productivity. Inactivity is directly linked with the long-term burden of COPD [42]; therefore, efforts to improve physical activity levels early in the disease process may be a first step towards reducing the overall burden of morbidity in these patients.

Recent advances in our understanding of COPD disease progression suggest that there are multiple patient outcome benefits attendant to treating symptoms of dyspnea and declining lung function early in the course of COPD (e.g. Stage II) [43]. Interestingly, the subgroup analysis among maintenance-naïve patients from the UPLIFT $^{\mathbb{B}}$ study demonstrated that tiotropium (in addition to any other respiratory medication except anticholinergics) achieved significant improvements in lung function, $\mathrm{HRQoL}$ (including a clinically important difference in St George's Respiratory Questionnaire total score over 4 years), and a reduction in the rate of decline of $\mathrm{FEV}_{1}(53 \mathrm{~mL} / \mathrm{year})$ compared with the control group (42 mL/year) [15]. In addition, it has recently been shown that dynamic hyperinflation significantly impedes activities of daily life [44]. Hence, it is reasonable to assume that improving dynamic hyperinflation may improve physical activity levels.

By focusing on GOLD Stage II COPD patients who had not yet been treated with maintenance pharmacotherapy, we expect to recruit a relatively large proportion of patients with an $\mathrm{FEV}_{1}>60 \%$ predicted normal who were more recently diagnosed/symptomatic, current smokers, younger and consequently still employed [28, 45] (thereby enabling 
Panel (A)

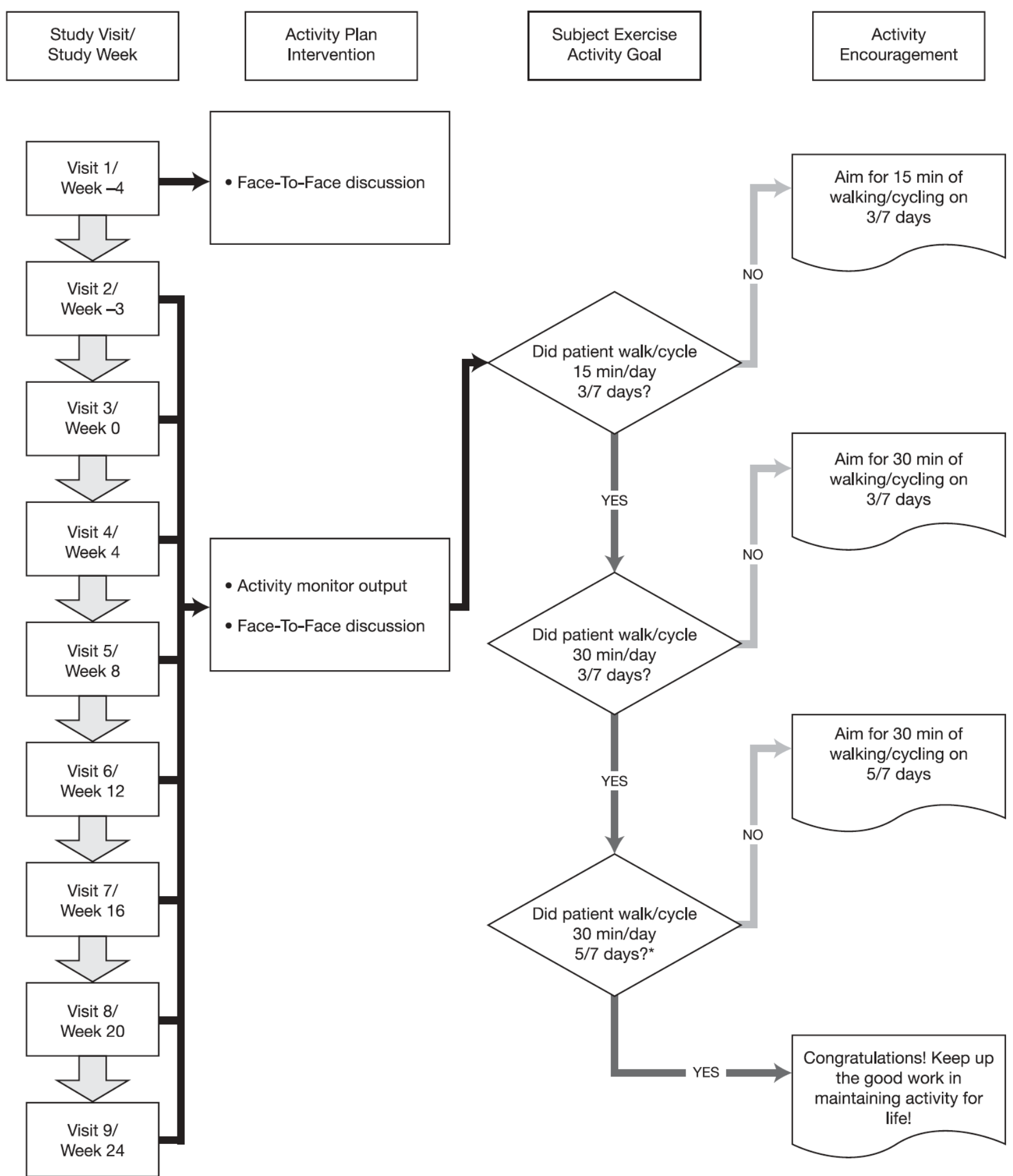


(Fig. 2) contd.....

Panel (B)

\begin{tabular}{|c|c|c|}
\hline $\begin{array}{l}\text { Study Visit/ } \\
\text { Study Week }\end{array}$ & $\begin{array}{l}\text { Activity Plan } \\
\text { Intervention }\end{array}$ & $\begin{array}{c}\text { Subject Endurance } \\
\text { Exercise Activity } \\
\text { Goal }\end{array}$ \\
\hline
\end{tabular}

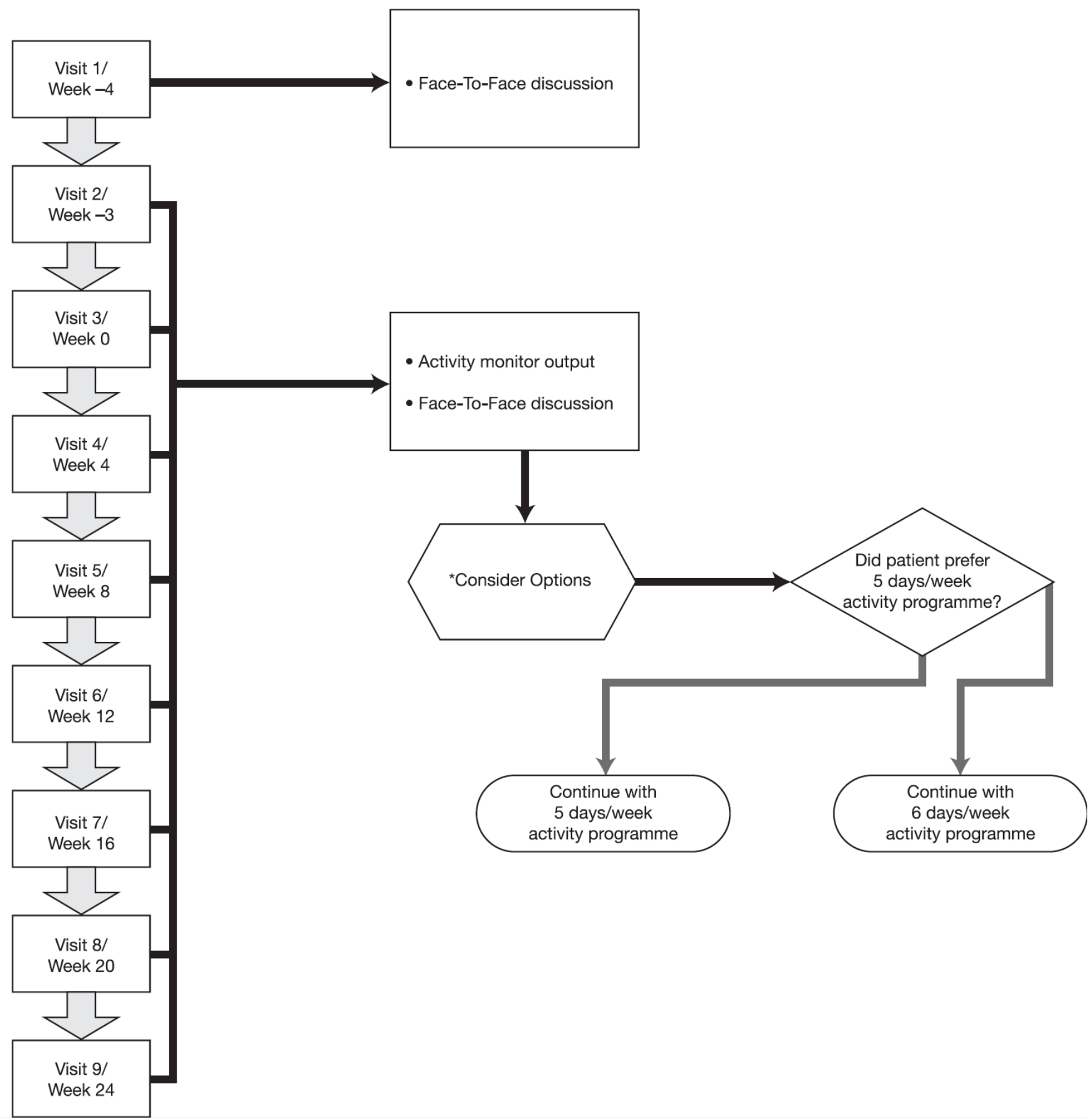

Fig. (2). Activity plan for (A) all patients and (B) active patients. Panel A - Patients are encouraged to walk or cycle at a "moderate" Modified BORG (CR-10) Score for breathlessness (3/10 to 4/10). *Patients whose physical activity exceeds 30 minutes of activity $>3$ METS five days a week, and who want to further increase their physical activity, proceed to Panel $\mathbf{B}$. Panel $\mathbf{B}$ - Patients are considered active if they exceed 30 minutes of physical activity $>3$ METS five days a week. *Options for advancing activity level include: 1) increase the time spent walking/cycling in increments of 5-10 minutes 5/7 days and/or walking more briskly; 2) gradually increase activity to 6/7 days; or 3) focus on lifestyle adjustments (e.g. use stairs instead of elevator). 
exploration of a work productivity outcome) [19], and a higher proportion of female patients, reflecting demographic changes reported in COPD [46, 47].

Physical activity assessment, reflecting real life, is a new patient-centered outcome measure in trials investigating the effects of pharmacotherapy in COPD. The selection of clinically meaningful outcomes for use in COPD clinical trials continues to evolve and expand from the more familiar focus on lung function, exacerbations, exercise, mortality, and HRQoL, towards more novel, functionally relevant patient-centered outcomes such as "free-living" activity. Maintaining activity for life in patients with COPD is a goal of effective treatment and management [5, 48], which impacts the clinical course of COPD by improving exercise tolerance, improving quality of life, decreasing exacerbations, and prolonging survival [1, 2, 17, 49]. The current study is, to our knowledge, the first multi-center clinical trial in COPD with pharmacologic intervention to assess lung function and objectively monitor activity coupled with interventions (behavioral modification and an individualized activity plan) aimed to increase/maintain activity in a full spectrum of GOLD Stage II maintenancenaïve COPD patients. Such data will expand our understanding of the long-term potential benefits of early treatment with maintenance pharmacotherapy in COPD.

An anticipated technical challenge in the current study is patient compliance with the activity monitor. Recent studies have suggested that patients may be insufficiently compliant in wearing activity monitors, even in single-center studies, or that technical malfunctions will occur $[50,51]$. However, a recent pilot study that used the same device in a cohort of COPD patients demonstrated activity monitor compliance rates of $>90 \%$ at each of the three study sites [7]. This study also demonstrated that, consistent with other studies $[6,8]$, the decline in physical activity occurred early in the course of the disease (GOLD Stage II) and that patients with COPD reduce their physical activity by reducing the intensity of activity while maintaining the number of steps. Thus monitoring only the number of steps may, therefore, overestimate the actual level of energy expenditure as light intensity exercise is maintained but moderate intensity activity ( $>3$ METS), which is important for health benefits, is markedly reduced. Lastly, the pilot study confirmed that the physical outcome measures used in the current study are reproducible. It is yet unclear what the impact of seasonality will be on the present study. Recent data from the UK suggest physical activity to be very variable with season [52]. Classical physiological measures of exercise tolerance may be more stable but may, from a patient's perspective, be less important.

A duration of 6 months was selected for the current study in order to allow for a gradual change in physical activity and for a true behavioral shift. Patients are supported with monthly activity and behavioral counseling (using motivational interviewing techniques), measurement of physical activity, and face-to-face meetings to discuss progress, with the aim of encouraging small monthly increases in physical activity; this has been successful in other clinical settings [53,54].

Data from the present trial may also help to define the importance of integrating several therapeutic interventions (activity monitoring, consultation on physical activity, the implementation of an activity plan, and pharmacotherapy) in the disease management of patients with COPD. A previous study has demonstrated success in enhancing exercise tolerance by combining pulmonary rehabilitation and tiotropium in patients with more severe COPD [18]. The present study will define the value of providing regular feedback on physical activity levels along with optimal pharmacotherapy and whether it suffices in enhancing physical activity levels in patients with moderate COPD.

\section{SUMMARY}

The current study is, to our knowledge, the first multicenter clinical trial in COPD with pharmacologic intervention that will assess lung function and physical activity outcomes, coupled with specific interventions (behavioral modification and an individualized activity plan) aimed towards increasing/maintaining activity in a full spectrum of GOLD Stage II maintenance-naïve COPD patients. While tiotropium improves laboratory-based exercise performance, the translation into improved physical activity outcomes in a large multi-center clinical trial has yet to be investigated and is the focus of the current study. The study design and methodology implemented here will advance our knowledge of the value of early intervention to relieve symptoms and improve lung function, and to provide further incentive to patients with COPD to be more physically active, prevent long-term morbidity and to enjoy a healthier lifestyle.

\section{ACKNOWLEDGEMENTS}

This study is funded by Boehringer Ingelheim International $\mathrm{GmbH}$ and Pfizer Inc. The authors acknowledge Natalie Barker of PAREXEL MMS who assisted in technical editing/writing, reference preparation and journal formatting of the manuscript, which was funded by Boehringer Ingelheim International $\mathrm{GmbH}$ and Pfizer Inc.

The authors also acknowledge the hard work of the Maintenance Naïve study team members: Carla Yunis, Solomon Klioze, Santosh Sutradhar, Lynette Bojko, Sinde Krapf, John Bullington, Andre Novikov, and Dr William Erhardt for his leadership and vision.
ABBREVIATIONS

$\begin{array}{ll}\text { ACTES } & =\text { Activity Evaluable Set } \\ \text { ANCOVA } & \text { Analysis of covariance } \\ \text { AUC } & =\text { Area under the curve } \\ \text { CCQ } & =\text { Clinical COPD Questionnaire } \\ \text { COPD } & =\text { Chronic obstructive pulmonary disease } \\ \text { CRQ } & =\text { Chronic Respiratory Questionnaire } \\ \text { FEV } & =\text { Forced expiratory volume in } 1 \text { second } \\ \text { FVC } & =\text { Forced vital capacity } \\ \text { GOLD } & =\text { Global Initiative for Chronic Obstructive } \\ \text { HRQoL } & \text { Lung Disease } \\ \text { MET } & =\text { Mealth-related quality of life }\end{array}$




\section{UPLIFT $^{\circledR}=$ Understanding Potential Long-Term Impacts on Lung Function with Tiotropium}

\section{REFERENCES}

[1] Garcia-Aymerich J, Lange P, Benet M, Schnohr P, Anto JM. Regular physical activity reduces hospital admission and mortality in chronic obstructive pulmonary disease: a population based cohort study. Thorax 2006; 61(9): 772-78.

[2] Garcia-Aymerich J, Lange P, Benet M, Schnohr P, Anto JM. Regular physical activity modifies smoking-related lung function decline and reduces risk of chronic obstructive pulmonary disease: a population-based cohort study. Am J Respir Crit Care Med 2007; 175(5): 458-63.

[3] Booth FW, Chakravarthy MV, Gordon SE, Spangenburg EE. Waging war on physical inactivity: using modern molecular ammunition against an ancient enemy. J Appl Physiol 2002; 93(1): 3-30.

[4] Watz H, Waschki B, Boehme C, Claussen M, Meyer T, Magnussen $\mathrm{H}$. Extrapulmonary effects of chronic obstructive pulmonary disease on physical activity: a cross-sectional study. Am J Respir Crit Care Med 2008; 177(7): 743-51.

[5] Rabe KF, Hurd S, Anzueto A, et al. Global strategy for the diagnosis, management, and prevention of chronic obstructive pulmonary disease: GOLD executive summary. Am J Respir Crit Care Med 2007; 176(6): 532-55.

[6] Pitta F, Troosters T, Spruit MA, Probst VS, Decramer M, Gosselink R. Characteristics of physical activities in daily life in chronic obstructive pulmonary disease. Am J Respir Crit Care Med 2005; 171(9): 972-7.

[7] Troosters T, Sciurba F, Battaglia S, et al. Physical inactivity in patients with COPD, a controlled multi-center pilot-study. Respir Med 2010; 104(7): 1005-11.

[8] Watz H, Waschki B, Meyer T, Magnussen H. Physical activity in patients with COPD. Eur Respir J 2009; 33(2): 262-72.

[9] Maltais F, Hamilton A, Marciniuk D, et al. Improvements in symptom-limited exercise performance over $8 \mathrm{~h}$ with once-daily tiotropium in patients with COPD. Chest 2005; 128(3): 1168-78.

[10] O'Donnell DE, Fluge T, Gerken F, et al. Effects of tiotropium on lung hyperinflation, dyspnoea and exercise tolerance in COPD. Eur Respir J 2004; 23(6): 832-40.

[11] Babb TG, Viggiano R, Hurley B, Staats B, Rodarte JR. Effect of mild-to-moderate airflow limitation on exercise capacity. J Appl Physiol 1991; 70(1): 223-30.

[12] Ofir D, Laveneziana P, Webb KA, Lam YM, O'Donnell DE. Mechanisms of dyspnea during cycle exercise in symptomatic patients with GOLD stage I chronic obstructive pulmonary disease. Am J Respir Crit Care Med 2008; 177(6): 622-9.

[13] Garcia-Rio F, Lores V, Mediano O, et al. Daily physical activity in patients with chronic obstructive pulmonary disease is mainly associated with dynamic hyperinflation. Am J Respir Crit Care Med 2009; 180: 506-12.

[14] O'Donnell DE, Laveneziana P, Ora J, Webb KA, Lam YM, Ofir D. Evaluation of acute bronchodilator reversibility in patients with symptoms of GOLD stage I COPD. Thorax 2009; 64(3): 216-23.

[15] Troosters T, Celli B, Lystig T, et al. Tiotropium as a first maintenance drug in COPD: secondary analysis of the UPLIFT trial. Eur Respir J 2010; 36: 65-73.

[16] Darkow T, Kadlubek PJ, Shah H, Phillips AL, Marton JP. A retrospective analysis of disability and its related costs among employees with chronic obstructive pulmonary disease. J Occup Environ Med 2007; 49(1): 22-30.

[17] Cooper CB. The connection between chronic obstructive pulmonary disease symptoms and hyperinflation and its impact on exercise and function. Am J Med 2006; 119(10 Suppl 1): 21-31.

[18] Casaburi R, Kukafka D, Cooper CB, Witek TJ Jr, Kesten S. Improvement in exercise tolerance with the combination of tiotropium and pulmonary rehabilitation in patients with COPD. Chest 2005; 127(3): 809-17.

[19] Reilly MC, Zbrozek AS, Dukes EM. The validity and reproducibility of a work productivity and activity impairment instrument. Pharmacoeconomics 1993; 4(5): 353-65.

[20] Quanjer PH, Tammeling GJ, Cotes JE, Pedersen OF, Peslin R, Yernault JC. Lung volumes and forced ventilatory flows. Report Working Party Standardization of Lung Function Tests, European
Community for Steel and Coal. Official Statement of the European Respiratory Society. Eur Respir J Suppl 1993; 16: 5-40.

[21] Quanjer PHE. Standardized lung function testing. Report Working Party Standardization of Lung Function Tests, European Community for Coal and Steel. Bull Eur Physiopathol Respir 1983; 19: 1-95.

[22] Fletcher CMC. Standardised questionnaire on respiratory symptoms: a statement prepared and approved by the MRC Committee on the Aetiology of Chronic Bronchitis (MRC breathlessness score). Br Med J 1960; 2: 1665.

[23] American Thoracic Society, American College of Chest Physicians. ATS/ACCP Statement on cardiopulmonary exercise testing. Am J Respir Crit Care Med 2003; 167(2): 211-77.

[24] Gibbons RJ, Balady GJ, Beasley JW, et al. ACC/AHA Guidelines for Exercise Testing. A report of the American College of Cardiology/American Heart Association Task Force on Practice Guidelines (Committee on Exercise Testing). J Am Coll Cardiol 1997; 30(1): 260-311.

[25] American Thoracic Society. Standardization of spirometry, 1994 update. Am J Respir Crit Care Med 1995; 152(3): 1107-36.

[26] Nici L, Donner C, Wouters E, et al. American Thoracic Society/European Respiratory Society statement on pulmonary rehabilitation. Am J Respir Crit Care Med 2006; 173(12): 1390413.

[27] Miller MR, Hankinson J, Brusasco V, et al. Standardisation of spirometry. Eur Respir J 2005; 26(2): 319-38.

[28] Langer D, Gosselink R, Sena R, Burtin C, Decramer M, Troosters T. Validation of two activity monitors in patients with COPD. Thorax 2009; 64(7): 641-42.

[29] Patel SA, Benzo RP, Slivka WA, Sciurba FC. Activity monitoring and energy expenditure in COPD patients: a validation study. COPD 2007; 4(2): 107-12.

[30] Dressendorfer RH, Haykowsky MJ, Eves N. Exercise for persons with COPD. American College of Sports Medicine. Available at: http://www.acsm.org [Accessed: July 24, 2009].

[31] US Department of Health and Human Services, Centers for Disease Control and Prevention, National Center for Chronic Disease Prevention and Health Promotion. Physical activity and health: A report of the Surgeon General. US Department of Health and Human Services. Available at: http://www.cdc.gov [Accessed: July 25, 2009].

[32] Pollock ML, Gaesser GA, Butcher J, et al. ACSM position stand: the recommended quantity and quality of exercise for developing and maintaining cardio respiratory in healthy adults and muscular fitness and flexibility. Med Sci Sports Exerc 1998; 30: 975-91.

[33] Haskell WL, Lee IM, Pate RR, et al. Physical activity and public health: updated recommendation for adults from the American College of Sports Medicine and the American Heart Association. Circulation 2007; 116(9): 1081-93.

[34] Miller WR, Rollnick S. Motivational Interviewing: Preparing People for Change. 1 ed. New York: Guilford Press 2002.

[35] Johansson G, Lindberg A, Romberg K, Nordstrom L, Gerken F, Roquet A. Bronchodilator efficacy of tiotropium in patients with mild to moderate COPD. Prim Care Respir J 2008; 17(3): 169-75.

[36] Cochran WG. Some methods for strengthening the common $\mathrm{chi}^{2}$ tests. Biometrics 1954; 10: 417-51.

[37] Mantel N, Haenszel W. Statistical aspects of the analysis of data from retrospective studies of disease. J Natl Cancer Inst 1959; 22: 719-48.

[38] van der Molen T, Willemse BW, Schokker S, ten Hacken NH, Postma DS, Juniper EF. Development, validity and responsiveness of the Clinical COPD Questionnaire. Health Qual Life Outcomes 2003; $1: 13$.

[39] Guyatt GH, Berman LB, Townsend M, Pugsley SO, Chambers LW. A measure of quality of life for clinical trials in chronic lung disease. Thorax 1987; 42(10): 773-8.

[40] Lacasse Y, Wong E, Guyatt G. A systematic overview of the measurement properties of the Chronic Respiratory Questionnaire. Can Respir J 1997; 4(3): 131-9.

[41] Schunemann HJ, Goldstein R, Mador MJ, et al. A randomised trial to evaluate the self-administered standardised chronic respiratory questionnaire. Eur Respir J 2005; 25(1): 31-40.

[42] Decramer M, Rennard S, Troosters T, et al. COPD as a lung disease with systemic consequences--clinical impact, mechanisms, and potential for early intervention. COPD 2008; 5(4): 235-56. 
[43] Decramer M, Celli B, Kesten S, Lystig T, Mehra S, Tashkin DP. Effect of tiotropium on outcomes in patients with moderate chronic obstructive pulmonary disease (UPLIFT): a prespecified subgroup analysis of a randomised controlled trial. Lancet 2009; 374(9696): 1171-8.

[44] Lahaije AJ, van Helvoort HA, Dekhuijzen PN, Heijdra YF. Physiologic limitations during daily life activities in COPD patients. Respir Med 2010; 104(8):1152-9.

[45] Calverley PM, Anderson JA, Celli B, et al. Salmeterol and fluticasone propionate and survival in chronic obstructive pulmonary disease. N Engl J Med 2007; 356(8): 775-89.

[46] Chapman KR. Chronic obstructive pulmonary disease: are women more susceptible than men? Clin Chest Med 2004; 25(2): 331-41.

[47] Glassberg MK, Murin S, Weisman IM. Sex, gender, and respiratory health and disease. Clin Chest Med 2004; 25(2): 237-408.

[48] National Institute for Clinical Excellence. Chronic obstractive pulmonary disease: national clinical guideline for management of chronic obstructive pulmonary disease in adults in primary and secondary care. Thorax 2004; 59 (Suppl I): 1-232.
[49] Pitta F, Troosters T, Probst VS, Spruit MA, Decramer M, Gosselink R. Physical activity and hospitalization for exacerbation of COPD. Chest 2006; 129(3): 536-44.

[50] Hecht A, Ma S, Porszasz J, Casaburi R. Methodology for using long-term accelerometry monitoring to describe daily activity patterns in COPD. COPD 2009; 6(2): 121-9.

[51] Walker PP, Burnett A, Flavahan PW, Calverley PM. Lower limb activity and its determinants in COPD. Thorax 2008; 63(8): 683-9.

[52] Sewell L, Singh SJ, Williams JE, Morgan MD. Seasonal variations affect physical activity and pulmonary rehabilitation outcomes. $\mathrm{J}$ Cardiopulm Rehabil Prev 2010; 30(5): 329-33.

[53] Kirk A, Mutrie N, MacIntyre P, Fisher M. Effects of a 12-month physical activity counselling intervention on glycaemic control and on the status of cardiovascular risk factors in people with Type 2 diabetes. Diabetologia 2004; 47(5): 821-32.

[54] Kirk A, Barnett J, Leese G, Mutrie N. A randomized trial investigating the 12-month changes in physical activity and health outcomes following a physical activity consultation delivered by a person or in written form in Type 2 diabetes: Time2Act. Diabet Med 2009; 26(3): 293-301.

(C) Troosters et al.; Licensee Bentham Open.

This is an open access article licensed under the terms of the Creative Commons Attribution Non-Commercial License (http://creativecommons.org/licenses/ by-nc/3.0/) which permits unrestricted, non-commercial use, distribution and reproduction in any medium, provided the work is properly cited. 